\title{
"Mal Banal" e América Latina: uma análise por meio da
}

\section{perspectiva Arendtiana}

\author{
"Mal banal" y América Latina : un análisis realizado por la perspectiva de
}

\author{
Arendt \\ "Banality of evil" and Latin America: an analysis by Arendt perspective
}

\begin{abstract}
Resumo
Dra. Sônia Maria Schio ${ }^{1}$

O presente ensaio visa a aproximar o conceito de "mal banal" utilizado por Arendt (1906-1975) para referir-se aos atos praticados durante os Totalitarismos da primeira década do séc. XX, o Nazista (1933-1945), em especial, com aqueles praticados na América, sobretudo a Espanhola, após o chamado "Descobrimento" (1492), exposto por Frei Bartolomé de las Casas (1474-1566). Para a prática do "mal banal", ou para a execução de atos maus, não é necessário que haja um agente maligno, religiosa ou ontologicamente tratando, ou com alguma espécie de fanatismo ou ideologia. Basta, apenas, alguém que não pense no que faz, não avalie os seus atos, não se coloque no lugar do outro, como fizeram os espanhóis, durante a denominada "Conquista da América" (14931550). A hipótese a ser desenvolvida é a de que, em ambos os eventos, a dignidade humana foi contornada porque o interesse de poucos prevaleceram: lucros, dominação, posse de terras, uso de mão de obra barata (escrava). Para que isso não continue a ocorrer, é preciso pensar. Torna-se necessário resistir e evitar que as práticas do mal aconteçam, e que as pessoas continuem sendo usadas como coisas, como meio, para algo que não seja a dignidade humana e a preservação do entorno.
\end{abstract}

Palavras-Chave: Arendt, "mal banal", Frei Bartolomé de Las Casas, ação, dignidade humana.

\section{Resumen}

Este ensayo pretende llevar el concepto de "mal banal" utilizado por Arendt (1906-1975) para referirse a los actos realizados durante el Totalitarismo de la primera década del siglo XIX, el Nazi (1933-1945), en particular con las que se practican en América, en particular el español, después del llamado "Descubrimiento" (1492), explicada por Fray Bartolomé de las Casas (1474-1566). Para la práctica del "mal banal", o para la ejecución de actos de maldad, no es necesario que haya un agente maligno, religiosas o ontológicamente, o con algún tipo de fanatismo o ideología. Simplemente, alguien que no piensa acerca de lo que hace, no evalúe sus actos, no se pone en lugar de otro, como hicieron los españoles, durante la llamada "Conquista de América". La hipótesis que se desarrolla es que en ambos eventos, la dignidad fue excluido porque los intereses de unos pocos prevalece: Ganancias, la dominación, la tenencia de la tierra, el uso de mano de obra barata (esclavos). Para no dejar que esto siga produciéndose, es necesario pensar. Es necesario resistir y evitar las prácticas de mal ocurra, y que las personas no siguen siendo utilizados como cosas, como un medio para algo que no es la dignidad humana y la preservación del entorno.

Palabras claves: Arendt, Frei Bartolomé de Las Casas, mal banal, accíon, dignidad humana.

\section{Abstract}

This essay aims to approximate the Arendt (1906-1975) "banality of evil" concept, initially developed to refer to acts performed during the Totalitarianism of the first decade of the XX century (the Nazi [1933-1945], in particular), with those acts practiced in America - especially by the Spanish, after the "Discovery" (1492), as exposed by Fray Bartolome de las Casas (1474-1566). The "banality of evil" is not necessary practiced by an evil agent, religious or ontologically treating, or by someone moved by fanaticism or ideology. The "evil" is practiced by someone who do not evaluate your actions and do not put yourself imaginatively in the place of

\footnotetext{
${ }^{1}$ Doutora em Filosofia; Universidade Federal de Pelotas; Pelotas, Rio Grande do Sul, Brasil; soniaschio@hotmail.com.
} 
another-for example, the Spanish colonizers during the "Conquest of America" (1493-1550). This essay develops the hypothesis that, in both events, the human dignity was circumvented for the benefits of other interests (such as profits, domination, ownership of land, slaving). The thought, as part of the life of the mind, is an individual act important to avoid the "banality of evil". Finally, it's necessary to resist and prevent the "evil", otherwise, people will continue to be used as things, as a means to something other than human dignity and for the preservation of the common world.

Key Words: Arendt, Bartolomé de Las Casas, banality of evil, action, human diginity

\section{Introdução}

Nos últimos setenta e um anos, tem-se falado (e ouvido) muito sobre os acontecimentos ocorridos durante a Segunda Guerra Mundial (1939-1945). E isso ocorre não apenas porque a guerra não é boa, porque nela morreram mais de 60 milhões de pessoas, ou que nela se destruiu parte do mundo conhecido, mas porque inaugurou algo jamais pensado, sequer em ficção: as "fábricas de morte". Em outros termos, que alguns seres humanos inventaram uma linha de produção para matar pessoas. Veja-se a planta baixa de um campo de concentração: ele foi planejado nos mínimos detalhes para tornar a morte de pessoas mais fácil, rápida, enfim, "eficiente".

Nesse contexto, atualmente tem-se a impressão que isso foi o "pior" evento da Humanidade ... Tal acepção, no entanto, gera problemas: é possível qualificar um evento que mata pessoas? Se quantificar é difícil, emitir juízos de valor torna-se quase impossível. Isso não descaracteriza os Totalitarismos (Nazista, Stalinista ou outro Fascismo) como absurdos ${ }^{2}$, apenas se pode pensar que estes, engendrados pelo ser humano contra o humano, infelizmente, não ocorreram apenas do séc. XX: os episódios da chamada "Conquista" da América pelos espanhóis (1493-1550), por exemplo, são momentos da História que precisam ser retomados não apenas pela Historiografia, mas também por outras áreas, como a Filosofia Política, sobretudo na América Latina.

A partir dessa perspectiva, as ações dos europeus, na chamada "América Espanhola", podem ser averiguadas sob um conceito contemporâneo, o de "mal banal", utilizado por Hannah Arendt (1906-1975) na busca de compreender o Totalitarismo Nazista (1933-1945), ou seja, os atos praticados na conhecida "Solução Final" (1942-1945), na qual pessoas foram exterminadas a partir de objetivos de pessoas e de grupos, mas não da dignidade humana. Frei Bartolomé de las Casas (1474-1566) expôs, de forma contundente, certas ações humanas praticadas na América Hispânica. Tais atos se configuraram como absurdos, inumanos,

\footnotetext{
${ }^{2} \mathrm{O}$ termo "absurdo". originário do latim absurdum, enquanto adjetivo, significa "contrário à razão, ao senso comum", isto é, com uma racionalidade mínima aceitável para um ser humano. Enquanto substantivo, trata daquilo "que é desprovido de propósito; despropósito, disparate: cair no absurdo. Projeto que não se pode realizar." Disponível em https://www.dicio.com.br/absurdo/. Acesso em 10/10/2016.
} 
incompreensíveis e inexplicáveis racionalmente. Eles objetivavam tornar as "Índias Ocidentais" (América) uma eficiente colônia de exploração, fonte de lucros e de produtos tanto para a Coroa quanto para a iniciativa privada.

Parece bastante importante, então, analisar os acontecimentos históricos, que se prolongam nos dias atuais ${ }^{3}$, nos mais diversos países da antiga Colônia Espanhola na América, para que, compreendendo-os, seja possível evitar que eles continuem a ocorrer, preservando pessoas e seus grupos étnicos, isto é, sua singularidade e sua diversidade - a sua dignidade humana, em outros termos. E isso não é responsabilidade apenas de governos ou de instituições, mas de cada um, enquanto ser humano, cidadão e habitante da Terra.

\section{A História}

Na Baixa Idade Média Europeia (séc. XI-XIV), vários fatores se articularam, como o aumento demográfico, a escassez de metais preciosos, a falta de matérias primas e de mercados, a conquista de Constantinopla pelos Turcos Otomanos (1454), fechando o Mar Mediterrâneo ao comércio com o Oriente, levando as maiores potências da época, Portugal e Espanha (em verdade, Castela e Aragão) a iniciarem buscas por rotas marítimas alternativas. Ou seja, lançaram-se à navegação do Oceano Atlântico com o objetivo de chegar às Índias: território rico em especiarias (cravo, noz-moscada, etc.) e metais preciosos. Assim, nessas viagens, as costas africanas foram exploradas pelos portugueses que chegaram à Índia, em 1498, sob o comando de Vasco da Gama (Portugal, 1460 ou 1469 - Índia, 1524). Também os espanhóis navegaram, porém, usando outro caminho, e chegaram ao Novo Mundo (1492), após denominado de "América". A conquista, iniciada em 1493, encerrou-se em torno de 1550, iniciando a chamada "colonização".

Cristóvão Colombo (1451-1506), um genovês, navegando sob a bandeira dos "Reis Católicos" (Isabel I, de Castela e Fernando II, de Aragão), chegou à América Central (Cuba ou República Dominicana, não há certeza sobre isso, segundo cubanos e dominicanos) em 1492. Para Aquino, Jesus e Oscar (1981, p. 48-49), chegaram a Santo Domingos, na atual República Dominicana, a qual recebeu o nome de "São Salvador". Colombo reconheceu a terra em nome dos Reis Espanhóis como se ela fosse desabitada. Inicialmente, a nova terra foi chamada de "Índias Ocidentais", posto que os navegadores pensavam ter chegado ao litoral da

\footnotetext{
${ }^{3}$ Por exemplo: "Cadáveres alinhados em calçadas sujas manchadas de sangue. alguns desses corpos, decapitados, pertencem muitas vezes a mulheres, velhos ou crianças. Os sobreviventes desapareceram na montanha ou na mata. Eventualmente, surgem correspondentes internacionais. Anotam números, detalhes rápidos - seu relato será breve e impessoal (...). Mesmo em meio à desinformação e ao desinteresse, não é muito difícil perceber que a absoluta maioria daqueles mortos - espalhados sob o sol tropical em alguma cidadezinha interiorana da América Central - são índios puros." (BUENO Apud LAS CASAS, 1985, p. 11)
} 
China ou nas ilhas que compõem atualmente o Japão. Américo Vespúcio (1454-1512), explorador e geógrafo italiano, acompanhou várias expedições pelas costas do Novo Mundo. ${ }^{4}$ E foi ele que, homenageado pelo geógrafo alemão Martín Waldseemüller, teve o prenome utilizado para denominar o novo continente: a América (AQUINO; JESUS; OSCAR, 1981, p. $51)$.

Nesse ciclo, o Brasil foi "descoberto", em 1500. Entretanto, o que é preciso destacar é que o objetivo das "Grandes Navegações" não foi a colonização ou o conhecimento, mas a exploração das riquezas e da mão de obra, e a dominação de novos território, expropriando seus antigos donos. Após a "conquista" iniciou o período chamado de Colonialismo. Nele continuaram a ocorrer o roubo, a morte, a exploração e o roubo de terras, das riquezas e da vida e dignidade das pessoas. Em outros termos, houve um grande genocídio por todo o continente. Há várias narrativas, mas elas nem sempre são lidas, retomadas, enfim conhecidas, como ocorre com o texto de Las Casas, entre outros existentes, tanto referindo-se à América Hispânica como ao restante do continente. ${ }^{5}$

Frei Bartolomé de Las Casas, nascido em Sevilha, em 1474, veio para a América duas vezes. A primeira, em 1502, retornando à Europa quatro anos depois e tornando-se sacerdote. A segunda, em 1511, também para a Ilha de Espanhola (República Dominicana), quando recebeu seu primeiro "lote de indíos" (encomienda) ${ }^{6}$. Nesse mesmo ano, ouviu o sermão do Padre Antonio de Montesinos (Espanha, 1475, Venezuela, 1540) ${ }^{7}$, defendendo os nativos do Novo Mundo. Após participar da conquista de Cuba, em 1513, ele recebeu uma nova "encomienda" e, em 1514, decidiu dedicar sua vida à defesa dos primeiros habitantes do Novo

\footnotetext{
${ }^{4}$ Ele escreveu a obra Novo Mundo - cartas de viagens e descobertas, a qual atualmente ainda está disponível,

${ }^{5}$ Por exemplo, Dee Brawn, com a obra Enterrem meu coração na curva do rio - índios contam o massacre de sua gente, que contém relatos sobre a expropriação dos nativos da América do Norte; e Darcy Ribeiro, com o livro intitulado Uirá sai a procura de deus, um estudo sobre a mitologia dos brasilíndios Tupis e dos seus sentimentos. Nesse texto, Uirá, um índio Urubu-Kaapor que, ao ter seu cotidiano devastado pela presença violenta e desagregadora dos homens "civilizados" no Maranhão, decide findar sua própria vida.

${ }^{6} \mathrm{~A}$ "encomienda" consistia em um grupo de indígenas confinados sendo entregues a um espanhol, denominado "encomindero", a quem pagavam tributos em forma de prestação de serviços. (AQUINO; JESUS; OSCAR, 1981, p. 60). Cada região possuía uma maneira específica para obter esse tipo de trabalho: a mitta, de origem inca; o cuatequil foram os mais conhecidos.

Um estudo comparativo entre esses sistemas e os "campos de concentração" Totalitários, os quais utilizaram trabalho forçado (em verdade, escravo) seria, certamente proveitoso e interessante.

${ }^{7}$ Ele disse: "Todos vós estais em pecado mortal. Nele viveis e nele morrereis, devido à crueldade e tiranias que usais com estas gentes inocentes. Dizei-me, com que direito e baseados em que justiça, mantendes em tão cruel e horrível servidão os índios? Com que autoridade fizestes estas detestáveis guerras a estes povos que estavam em suas terras mansas e pacíficas e tão numerosas e os consumistes com mortes e destruições inauditas? Como os tendes tão oprimidos e fatigados, sem dar-lhes de comer e curá-los em suas enfermidades? Os excessivos trabalhos que lhes impondes, os faz morrer, ou melhor dizendo, vós os matais para poder arrancar e adquirir ouro cada dia ... Não são eles acaso homens? Não têm almas racionais? Vós não sois obrigados a amá-los como a vós mesmos? Será que não entendeis isso? Não o podeis sentir?" Disponível em https://pt.wikipedia.org/wiki/Ant\%C3\%B3nio_de_Montesinos. Acesso em 10/10/2016.
} 
Mundo. No ano seguinte, tornou-se Dominicano e passou a atuar mais efetivamente: em 1515, Las Casas viajou à Espanha para advogar pelos ameríndios, mas seus protestos não foram ouvidos. Ele não desistiu e continuou a militar em favor dos povos nativos, escrevendo e navegando para reunir-se com autoridades hispânicas. Entretanto, havia muitos opositores às suas concepções, mesmo entre os religiosos. Ressalte-se, entre eles, Frei Juan Cabedo, defensor da escravização dos povos americanos.

Las Casas registrou muitas situações, ocorridas e experenciadas por ele, nesse período, relativa aos nativos da América Espanhola, e que podem ser nomeadas de "genocídio"8. Por exemplo

\begin{abstract}
Na ilha Espanhola que foi a primeira, como se disse, a que chegaram os espanhóis, começaram as matanças e perdas de gente, tendo os espanhóis começado a tomar as mulheres e filhos dos índios para deles servir-se e usar mal e a comer seus víveres adquiridos por seus suores e trabalhos. (...) Os espanhóis lhes davam bofetadas, socos e bastonadas e se ingeriam em sua vida. (...) entravam nas vilas, burgos e aldeias, não poupando nem as crianças nem os homens velhos, nem as mulheres grávidas e parturientes e lhes abriam o ventre e as faziam em pedaços. (Las Casas, 1985, p. 31-32)
\end{abstract}

Pode-se aventar explicações como o fito de explicar, ou de minimizar, a amplitude dos acontecimentos: a situação vivida na Europa, naquele tempo, em que a guerra sangrenta era considerada normal, pois sua ocorrência era habitual; ou que não havia uma legislação que distinguisse (e protegesse) civis e soldados, entre outras possibilidades. Porém, tais tentativas não justificam a maneira como agiram os conquistadores. Dito outramente, poderiam advogar em favor dos conquistadores somente aqueles que consideram que poderia ser aceitável apossar-se daquilo que é de outro, porque é valioso e uma autoridade consente ou comanda, mesmo em outro território, pois possui mais capacidade cultural ("levar a civilização", "tornálos cristãos") ou bélica, na qual há o uso da força e a violência, por meio de instrumentos como as armas de fogo, e de cavalos (desconhecidos e temidos pelos ameríndios) ou outros expedientes (ou até todos esses em conjunto). Mas isso seria "mentir para si mesmo", porque tais atitudes têm denominações conhecidas: pilhagem, latrocínio, homicídio, genocídio.

\footnotetext{
${ }^{8}$ Denotativamente, genocídio é o "extermínio que, feito de maneira deliberada, aniquila (mata) uma comunidade, um grupo étnico ou religioso, uma cultura e/ou civilização etc. Ex: o genocídio dos índios das Américas; Massacre que atinge um grande número de pessoas (populações ou povos); Ação de aniquilar grupos humanos através da utilização de diferentes formas de extermínio como: a pobreza ou a fome em certas regiões do mundo; sequestro permanente de crianças e refugiados etc." Disponível em https://www.dicio.com.br/genocidio/. Acesso em 11/10/2016.
} 
RELACult - Revista Latino-Americana de Estudos em Cultura e Sociedade

Revista Latinoamericana de Estudios en Cultura y Sociedad | Latin American Journal of Studies in Culture and Society

V. 02, Ed. Especial, dezembro, 2016, p. 42-53| periodicos.claec.org e-ISSN 2016/Atual: 2525-7870 | e-ISSN 2015/2016: 2447-018X

\section{Os eventos: a Conquista da América e o Totalitarismo Nazista}

Os Sistemas Totalitários mais conhecidos do séc. XX foram o Nazista e o Stalinista. Existiram, porém, outros que possuíram alguns atributos assemelhados, como o Fascismo Italiano e o Regime Franquista, atendo-se apenas ao Ocidente Europeu. Tais Regimes possuem as mais variadas características: uso da propaganda, de polícia secreta, da mentira política, da tortura, da delação, de inimigo objetivo (comunista, homossexual, judeu, cigano, polonês, negro, testemunha de Jeová, por exemplo), de campos de concentração com trabalhos forçados, extermínio. Soma-se a isso, a guerra para a anexação de territórios, como o da Polônia, da Tchecoslováquia, entre outros.

A "conquista da América", por seu turno, não precisou de fábricas de morte, pois as pessoas foram mortas em suas cidades, junto com suas famílias, incluindo velhos e crianças, doentes ou grávidas, como demonstram os relatos. E o objetivo foi lhes subtrair as terras, os tesouros e, muitas vezes, explorar o trabalho, conforme descrito por Las Casas. ${ }^{9}$ Entretanto, há poucas estatísticas sobre o número de mortos. Sabe-se que territórios inteiros ficaram sem população autóctone, como a atual República Dominicana, a chamada de Hispanõla (Espanhola), naquele tempo. Mesmo com dúvida sobre a validade dos dados, Las Casas (1985, p. 29) afirma, em um relato sem a citação das fontes, que

Podemos dar conta boa e certa que em quarenta anos, pela tirania e diabólicas ações dos espanhóis, morreram injustamente mais de doze milhões de pessoas, homens, mulheres e crianças; e verdadeiramente eu creio, e penso não ser absolutamente exagerado, que morreram mais de quinze milhões.

Nessa perspectiva, segundo Aquino, Jesus e Oscar (1981, p. 57),

não se pode negar que o comportamento do conquistador foi sempre violento: matou milhares de indígenas, saqueou suas riquezas, explorou a força de trabalho, desestruturou o mundo nativo mediante uma conquista que não foi unicamente militar, mas também racial, religiosa e econômica, cultural e política.

Em outros termos, "a dizimação de populações indígenas e as condições subumanas a que ficavam submetidas as comunidades encomendadas provocaram conflitos entre os colonos e as ordens religiosas, sobretudo os jesuítas" (AQUINO; JESUS; OSCAR, 1981, p. 60). E assim agiram também outros europeus: os portugueses, os ingleses, os holandeses, os franceses, além de algumas outras comunidades europeias.

\footnotetext{
${ }^{9}$ Por exemplo, em Las Casas (1985, p. 30): a causa foi o ouro, a avareza.
} 
Nesse contexto, várias questões surgem e ressurgem, como por exemplo, qual é o motivo (ou os motivos) que levam um dos eventos a ser comentado, exposto, estudado - os acontecimentos provocados pelo Nazismo (1933-1945), enquanto o outro é, ou está, quase esquecido - aqueles referentes à conquista do ameríndio pelos europeus (1493-1550). Em outros termos, a morte não pode ser admitida: existencial e politicamente pensando, ela é o final do percurso da pessoa, de sua História. Ou seja, quando se trata da morte de um ser humano, não há apenas a extinção biológica, pois o humano possui também aspectos simbólicos, culturais, políticos etc. Assim, apesar da morte ser natural, ela não é um fato comum porque envolve a dignidade humana, a qual precisa ser resguardada. Se cada vida humana tem valor, um conjunto delas possui uma importância incomensurável. Nesse sentido, um genocídio coloca a Humanidade, presente e futura, em questão. Sob esse prisma, não há textos em que ambos os eventos (e outros genocídios que ocorreram e que estão acontecendo) sejam citados em conjunto, mesmo que os objetivos foram bastante parecidos: lucros para alguns grupos em detrimento dos bens, do trabalho e da vida de outros.

Além disso, chama a atenção o comportamento de pessoas que receberam e executaram as ordens, mesmo não fazendo parte do grupo que seria diretamente beneficiado. Segundo Aquino, Jesus e Oscar (1981, p. 55), a participação da Coroa Espanhola na América, por exemplo, foi reduzida, cabendo à iniciativa particular realizar a conquista. E o fizeram por meio das "capitulações", contratos, nos quais os interessados representavam os Reis Católicos no Novo Mundo. Como escreveu Las Casas (1985, p. 29),

Aqueles que foram da Espanha para esses países (e se tem na conta de cristãos) usaram de duas maneiras gerais e principais para extirpar da face da Terra aquelas míseras nações. Uma foi a guerra injusta, cruel, tirânica e sangrenta. Outra foi matar todos aqueles que podiam ainda respirar ou suspirar e pensar em recobrar a liberdade (...) com a mais horrível e áspera servidão a que jamais se tenham submetido homens ou animais.

Assim, outra característica aproxima os dois eventos: atos monstruosos, incomensuráveis, foram praticados por pessoas que não tinham qualquer psicopatia, fanatismo ou ódio pelo inimigo. Nesse momento, as reflexões de Arendt sobre o "mal banal" podem auxiliar, se não na compreensão de tais atitudes, ao menos na motivação para a investigação delas.

\section{A "banalidade do mal"}

Quando as notícias sobre o extermínio ("Solução Final", iniciada após a Conferência de Wansee, em 1492) começaram a ser divulgadas (em torno de 1943), a maioria das pessoas, 
refugiados ou não, ficaram descrentes. Parecia-lhes impossível que tais atos pudessem estar ocorrendo ou de terem acontecido. Com o passar do tempo e com as derrotas Nazistas, até o final, em oito de maio de 1945, tornou-se impossível continuar duvidando: testemunhos, fotos, filmes, foram sendo divulgados. ${ }^{10}$ Muitas pessoas passaram a questionar-se sobre os motivos que levaram pessoas, nos mais diversos países europeus, mas em especial na Alemanha (mas, é importante ressaltar, nem todo alemão foi nazista) a tais atitudes.

Arendt deixou a Alemanha em 1933, devido à ascensão progressiva de Hitler e de seus colaboradores e simpatizantes ao Governo alemão. Ela vivenciou a situação e procurou entendê-la: inicialmente denominou de "mal radical" às atitudes praticadas (na obra Origens do Totalitarismo, publicada em 1951). Após o Julgamento de um funcionário Nazista (Adolf Eichmann; Alemanha, 1906 - Jerusalém, 1962), ocorrido em 1961-1962, ela alterou a denominação para "mal banal": atos cometidos sem uma raiz, seja de maldade, de patologia, de ideologia, de religião, mas enorme em seus resultados. Ela (ARENDT, 1992, p. 6) escreveu:

O que me deixou aturdida foi que a conspícua superficialidade do agente tornava impossível retraçar o mal incontestável de seus atos, em suas raízes ou motivos, em quaisquer níveis mais profundos. Os atos eram monstruosos, mas o agente - ao menos aquele que estava agora em julgamento - era bastante comum, banal e não demoníaco ou monstruoso.

Entretanto, esse "mal político" não é perdoável, sequer punível. Ele é assombroso porque é praticado sem uma intenção, mas ele atinge e destrói não apenas as pessoas e suas famílias e amigos, mas o ser humano, ao desrespeitar a dignidade humana.

Na busca de ser equânime, pode-se expor o que o réu afirmou para defender-se, em seu julgamento. Nos termos de Arendt (1999, p. 152. Grifos da autora.),

Ele cumprira o seu dever, como repetiu insistentemente à polícia e à corte; ele não só obedecia ordens, ele também obedecia à lei. (...) [com tais explicações,] ele acabou completamente confuso e terminou frisando alternativamente as virtudes e os vícios da obediência cega, ou da obediência cadavérica (Kadavergehorsam), como ele próprio chamou.

A partir dessa perspectiva, pode-se questionar o que um "conquistador" do Novo Mundo teria dito se ele estivesse do lugar de Eichmann, isto é, no banco dos réus. Como ele explicaria suas atitudes? Alguém como Cortés (Hernán Cortés de Monroy y Pizarro

\footnotetext{
${ }^{10}$ Sabe-se que até hoje há pessoas que duvidam que "tais coisas" tenham ocorrido, porém esse tema apenas tangencia o objetivo do presente Ensaio.
} 
Altamirano, Espanha, 1485-1547), que conquistou o México, em 1519, buscaria expor seus motivos? Segundo relato de Léon-Portilha (1985, p. 29 e 32):

pois ali em Huitzillan, lhes sai ao encontro Motecuhzoma [Montezuma]. Logo presenteia o capitão [Cortés], que comanda os demais, e os que vêm guerrear. Oferece-lhes presentes, põe-lhes flores ao pescoço, (...) Em seguida, põe em frente a eles os colares de ouro, toda espécie de dons, gentilezas de boas-vindas. (...) [após mudarem de localização, os espanhóis] entram no pátio sagrado para matar a todos. Vão a pé, levam seus escudos de madeira, alguns de metal, e suas espadas. (...) O sangue dos guerreiros [astecas] escorria como água: como água que se alaga, e o mau cheiro do sangue e das entranhas, que pareciam arrastar-se, tomava conta do ar. Os espanhóis andavam por toda parte a procura das casas da comunidade: por toda parte davam estocadas.

Sobre a região de Trindade e arredores, Las Casas (1985, p. 85) descreveu que "de toda essa costa, que era muito povoada, tiraram mais de dois milhões de almas por meio do rapto". Sobre os "coletores de pérolas", os Lucaios, ainda segundo ele (LAS CASAS, 1985, p. 85-86), a escravidão que lhes foi imposta foi a pior (se assim se pode afirmar, e o Frei o sabia), pois ele narrou que

[os espanhóis] Põem-nos no mar, três ou quatro braças dentro d'água, desde a manhã até o cair do sol, onde ficam continuamente nadando, sem respirar, arrancando as ostras onde se engendram as pérolas. (...) dão-lhes uma vida tão horrível que se consomem e morrem em alguns dias, pois é impossível que os homens possam viver tanto tempo sob a água sem tomar alento e expostos ao frio contínuo; e, assim, morrem comumente expelindo sangue pela boca.

Talvez, muitos dos espectadores ficassem paralisados se Cortés ou um feitores de Lucaios dissesse que obedecia a ordens, às leis dos Reis Católicos, ao seu dever de soldado, como o fizera Eichmann. E o argumento de que não há civilização sem sacrifícios; que o progresso exige mudanças; que o "preço" por um futuro melhor tem que ser "pago" sem hesitação. Ou ainda que a História está repleta de acontecimentos como os desta Conquista e que pode-se citar vários exemplos deles. Se tais argumentos parecerem válidos, pode-se, mais uma vez, retornar ao pensamento de Arendt. Ela (ARENDT, 1992, p. 60), na obra A vida do Espírito, afirmou que

Clichês, frases feitas, adesão a códigos de expressão e conduta convencionais e padronizados têm a função socialmente reconhecida de nos proteger da realidade, ou seja, da atenção do pensamento feita por todos os fatos e acontecimentos em virtude de sua mera existência.

Mesmo que não haja fórmulas para impedir a ocorrência de atrocidades, tais como os genocídios expostos nos dois eventos, Arendt sugere que cada ser humano precisa adotar a 
posição de cidadão de sua comunidade, região, país; que é necessário resistir ao mal: aos pretensos ganhos, sejam eles econômicos, sociais ou outros; e evitar de cometer o mal por não se perguntar o que faz, por que faz. E mais, ela retoma o pensamento de Kant, da Terceira Crítica $(1790)^{11}$, afirmando que "podemos 'alargar' o próprio pensamento a ponto de considerar o pensamento dos outros. (...) O pensamento crítico é possível à medida que os pontos de vista dos outros estão abertos à inspeção." (ARENDT, 1993, p. 56-57).

Em outros termos, a dignidade humana apenas pode ser mantida pelos seres humanos quando reunidos em um ambiente público e político. Ou seja, quando as pessoas estão em situação de igualdade, de respeito ao diferente ( singularidade $^{12}$ ), podendo ouvir e falar sem coação, decidindo e agindo em conjunto, a vida humana, do planeta, dos demais seres vivos pode ser preservada. Isso porque a pluralidade ${ }^{13}$ não pode ser contornada e esquecida, e a liberdade, com espontaneidade, é essencial para que cada habitante do Planeta possa considerar-se humano.

\section{Considerações Finais}

Retomar as questões propostas, em um ensaio, significa uma tentativa de aproximar eventos distantes, tanto no tempo quanto nas discussões teórico-científicas. Dito de outro modo, buscar compreender eventos diferentes oportuniza que eles sejam analisados a partir de situações e de características que, em um primeiro momento, parecem distantes e desconexas. Nos casos em questão, porém, há variadas semelhanças, como os objetivos da eliminação de pessoas (apossar-se de seus pertences, ampliar territórios e explorá-los, desvalorizar o diferente, usar sua mão de obra, entre outros). E ainda, que foram humanos, seguindo ordens, que executaram tais atrocidades. Por que eles obedeceram? Eles nada sentiram ao presenciar o sofrimento e a morte dos outros? Por que não pensaram sobre o que faziam, não se colocaram no lugar daqueles que estavam sendo expropriados, explorados, mortos? Ou dos velhos, das crianças?

\footnotetext{
11 "Homens = criaturas limitadas à Terra, vivendo em comunidades, dotadas de senso comum, sensus communis, um senso comunitário, não-autônomas, cada qual precisando da companhia do outro, mesmo para o pensamento ("a liberdade de escrita") = primeira parte da Crítica do juízo: juízo estético." (ARENDT, 1993, p. 37)

${ }^{12}$ Para Arendt, a singularidade compõe a condição humana. Ou seja, cada ser humano é único, irrepetível e insubstituível.

13 A pluralidade, para Arendt, compõe a condição humana junto à singularidade, à natalidade, à vida e à mundaneidade. A "pluralidade" refere-se ao fato que a Terra é um globo, e assim, cada ser humano é 'vizinho' do outro, mesmo que hajam distâncias geográficas. Nesse sentido, é preciso compartilhar o planeta, preservá-lo, deixá-lo para as gerações futuras, independente das diferenças, sejam elas quais forem (étnicas, religiosas, por exemplo). (Cf. ARENDT, na obra A condição humana; SCHIO, 2012)
} 
Por um outro prisma, ressurgem algumas perguntas: por que um evento parece ser mais valorizado que outro? Porque um aparentemente está sendo esquecido com o passar do tempo e o outro, não? No cotidiano deste continente, muitos povos autóctones (nativos, índios ou ameríndios, não importa a denominação) continuam a ser dizimados, desrespeitados por pessoas e por governos. Não há consideração pelo outro, sua cultura, propriedade ou vida ${ }^{14}$. Assim, parece evidenciar-se que é preciso mais do que leis: necessita-se retomar os fatos, alterar as mentalidades colonizadas por meio da memória, não esquecendo os eventos do passado, com suas consequências no presente, nem assumindo uma atitude de autocomiseração. Deve-se fazer um esforço cidadão, então político, em prol da dignidade humana, visando ao futuro, mas não sem o passado, que é sua base, e enfatizando o presente, momento do convívio com os outros, da conversa, da superação dos entraves (sejam quais forem) e da ação.

\section{Referências}

AQUINO, Rubim Santos Leão de; et al. História das Sociedades Americanas. Rio de Janeiro: Livraria Eu e Você, 1981.

ARENDT, Hannah. Origens do totalitarismo - antissemitismo, imperialismo e totalitarismo. São Paulo: Cia das Letras, 1989.

A vida do espírito: o pensar, o querer, o julgar. Rio de Janeiro: RelumeDumará/UFRJ, 1991.

Lições sobre a filosofia Política de Kant. Rio de Janeiro: Relume-Dumará, 1993. 1999.

Eichmann em Jerusalém: um relato sobre a banalidade do mal. Paris: Gallimard, Responsabilidade e Julgamento. São Paulo : Cia das Letras, 2004.

LAS CASAS, Frei Bartolomé. O Paraíso Destruído: a sangrenta história da conquista da América Espanhola. PortoAlegre: L\&PM, 1984.

LÉON-PORTILLA. A conquista da América vista pelos índios: relatos astecas, maias e incas. Trad. de Herldo Barbuy; Apres e notas de Eduardo Bueno. 2 ed, Petrópolis: Vozes, 1985.

\footnotetext{
${ }^{14}$ Nesse sentido, segundo a Relatoria Especial da Organização das Nações Unidas (ONU) sobre os direitos dos povos indígenas, o Brasil assiste a retrocessos preocupantes na proteção dos direitos destes os povos. Como exemplos são citados: a proposta de emenda à Constituição (PEC) 215, o qual transfere ao Congresso Nacional a decisão final sobre a demarcação de terras, a interrupção dos processos de demarcação (existem aproximadamente 20 terras indígenas pendentes de homologação pela Presidência da República), a falta de proteção das terras indígenas contra as atividades ilegais e aos megaprojetos de infraestrutura em territórios indígenas ou perto deles (como a Hidrelétrica de Belo Monte). Mais informações disponíveis em: http://agenciabrasil.ebc.com.br/direitos-humanos/noticia/2016-03/onubrasil-teve-retrocessos-preocupantes-naprotecao-dos-indigenas. Acesso em:10/10/2016.
} 
SCHIO. Sônia Maria. Hannah Arendt: história e liberdade (da ação à reflexão), 2 ed., Porto Alegre: Clarinete, 2012.

Hannah Arendt: o mal banal e o julgar. Revista Veritas. Porto Alegre, v. 56, n. 1, jan./abr. 2011, p. 127-135. Disponível em:

https://bibliotecadafilo.files.wordpress.com/2013/10/1-sohio-hannah-arendt-o-mal-banale-o-julgar.pdf. acesso em 09/10/2016.

VESPÚCIO, Américo. Novo Mundo - cartas de viagens e descobertas. Porto Alegre: LP\&M, 1984. 